\title{
The role of mouthwash sampling in SARS-CoV-2 diagnosis
}

\author{
Asaf Biber ${ }^{1,2} \cdot$ Dana Lev $^{1,2} \cdot$ Michal Mandelboim ${ }^{3} \cdot$ Yaniv Lustig ${ }^{3} \cdot$ Geva Harmelin $^{4} \cdot$ Amit Shaham $^{4} \cdot$ Oran Erster $^{3}$. \\ Eli Schwartz ${ }^{1,2}$
}

Received: 5 May 2021 / Accepted: 20 July 2021 / Published online: 3 August 2021

(c) The Author(s), under exclusive licence to Springer-Verlag GmbH Germany, part of Springer Nature 2021

\begin{abstract}
Background The current practice of COVID-19 diagnosis worldwide is the use of oro-nasopharyngeal (ONP) swabs. Our study aim was to explore mouthwash (MW) as an alternative diagnostic method, in light of the disadvantages of ONP swabs. Methods COVID-19 outpatients molecular-confirmed by ONP swab were repeatedly examined with ONP swab and MW with normal saline $(0.9 \%)$. Other types of fluids were compared to normal saline. The Cq values obtained with each method were compared.

Results Among 137 pairs of ONP swabs and MW samples, 84.6\% (116/137) of ONP swabs were positive by at least one of the genes (N, E, R). However MW detected 70.8\% (97/137) of samples as positive, which means 83.6\% (97/116) out of positive ONP swabs, missing mainly $\mathrm{Cq}$ value $>30$. In both methods, the $\mathrm{N}$ gene was the most sensitive one. Therefore, MW samples targeting $\mathrm{N}$ gene, which was positive in 95/137 (69.3\%), are comparable to ONP swabs targeting $\mathrm{E}$ and $\mathrm{R}$ genes which gave equal results—95/137 (69.3\%) and 90/137 (65.7\%), respectively.

Comparing saline MW to distilled water gave equal results, while commercial mouth-rinsing solutions were less sensitive. Conclusions MW with normal saline, especially when tested by $\mathrm{N}$ gene, can effectively detect COVID-19 patients. Furthermore, this method was not inferior when compared to R and E genes of ONP swabs, which are common targets in many laboratories around the world.
\end{abstract}

Keywords Gargling · Saliva · Throat-wash $\cdot$ COVID-19 $\cdot$ Mouth rinse

\section{Introduction}

The COVID-19 pandemic has prompted an unprecedented global consumption of diagnostic equipment, and the demand for diagnostic tests continues to rise. As of September 4, 2020, the WHO has shipped 9,826,519 swabs worldwide to insure supply for low-middle-income countries [1].

Asaf Biber, and Dana Lev contributed equally to this work.

Dana Lev

danalev7@gmail.com

1 The Center for Geographic Medicine and Tropical Diseases, Sheba Medical Center, Tel Hashomer, Ramat Gan, Israel

2 Sackler Faculty of Medicine, Tel-Aviv University, Tel-Aviv, Israel

3 Central Virology Laboratory, Ministry of Health, Sheba Medical Center, Tel Hashomer, Ramat Gan, Israel

4 Department of Emergency Medicine, Sheba Medical Center, Tel Hashomer, Ramat Gan, Israel
In light of the tremendous need to increase the availability of diagnostic tests, the NIH launched the Rapid Acceleration of Diagnostics (RADx) program to support the development, production, and deployment of rapid accurate tests [2].

SARS-CoV-2, the etiological agent of the ongoing COVID-19 pandemic, is transmitted through respiratory droplets. Patients with COVID-19 have demonstrated high viral loads in their upper and lower respiratory tracts beginning as early as 5-6 days before the onset of symptoms [3-6]. The current methods of diagnosis of SARS-CoV-2 include detection of the virus by genomic techniques using reverse transcription polymerase chain reaction (RT-PCR) [7].

Oro- or nasopharyngeal sampling is currently the gold standard for diagnosis, with a range of sensitivity results, presumably due to different collection methods and laboratory techniques.

The major disadvantages of nasopharyngeal swabs are the necessity of swabs and medium, which are largely unavailable in many parts of the world, their cost, the need to train 
workers to collect the specimens, as well as discomfort to the patient and the potential risk of infection for the examiner. These disadvantages motivate efforts to explore different sampling methods.

One proposed method to replace the use of swabs was the collection of saliva. This method was tested in several recent studies [8], with contradicting conclusions when compared to nasopharyngeal swabs. For example, in a clinical trial conducted in Canada, which compared 91 pairs of nasopharyngeal swabs and saliva samples, sensitivity was $89 \%$ for nasopharyngeal swabs and significantly less for salivaonly $72 \%$ [9]. The difference in sensitivity was greatest for sample pairs collected later during the illness course [9]. On the contrary, the same comparison was made in Connecticut, USA, for 70 patients and yielded a higher percentage of positive saliva samples than nasopharyngeal swab samples up to 10 days after the diagnosis. In addition, more copies of SARS-CoV-2 RNA were detected in the saliva specimens [10]. Nonetheless, in August 2020, the FDA issued an emergency use authorization (EUA) for a self-collecting saliva kit, named SalivaDirect-a RT-qPCR test from saliva collected by healthcare providers, which uses proteinase $\mathrm{K}$ and heating to extract RNA [11].

Herein, we present the utility of MW samples for the detection of SARS-CoV-2, a method that has not been thoroughly examined. In contrast to ONP swabs, MW is a noninvasive, simple, and inexpensive test that can be easily performed by the patient him or herself.

This study examined a variety of fluids for mouth rinsing.

\section{Methods}

\section{Study design}

This was a community-based, prospective trial, to evaluate the effectiveness of MW in the detection of SARS-CoV-2 as a diagnostic method. The study was conducted mainly in non-hospital facilities dedicated for COVID-19 patients in isolation. Patients were followed during their stay in these facilities.

Ethical approval was obtained from Sheba Medical Center and informed consent was obtained from all patients. The trial was done in accordance with the principles of the Declaration of Helsinki.

\section{Study population}

The study population included adult men and non-pregnant women ( $>18$ years old), with molecular confirmation of COVID-19 by RT-PCR. All patients were either asymptomatic or with mild symptoms.

\section{Exclusion criteria}

Patients with age under 18 years and patients with severe infection (defined as need for invasive or noninvasive ventilator support, ECMO, or shock requiring vasopressor support) were not included.

\section{Sample collection methodology}

Between July and September 2020, we collected 361 samples from a total of 96 confirmed COVID-19 outpatients: 137 ONP swabs, 137 saline MW samples, 59 distilled water wash, 12 commercial MW solution containing alcohol, and 16 commercial MW solution without alcohol.

Patients were repeatedly examined both for MW and ONP swabs. Due to the fact that the sensitivity of the test is affected by the examiner who performs the swab, and differences between labs, the same medical staff performed the swab sampling during the entire trial. All RT-qPCR tests were conducted by the Israel Central Virology Laboratory, using the same protocol, as detailed below.

\section{Oro-nasopharyngeal swabs procedure}

The sampling guidelines in Israel instruct to insert first a swab into the posterior pharynx and tonsillar areas, followed by inserting a flexible swab through the nostril to the nasopharynx. The two swabs are placed together in a single tube to maximize test sensitivity [12]. Therefore, the standard policy in Israel is actually an ONP swab testing.

\section{Mouthwash sampling}

Patients were asked to rinse and gargle $10 \mathrm{cc}$ of normal saline $(0.9 \%)$ for about $10-20 \mathrm{~s}$ and then spit the fluid into a sterile container.

In addition, other solutions were tested with a small number of patients, in order to compare it to the standard saline solution, which included the following:

a. Distilled water

b. Commercial mouthwash containing alcohol (Listerine®, manufactured by Johnson \& Johnson)

c. Commercial mouthwash without alcohol (Orbitol®), manufactured by Cosmopharm Ltd.)

All samples were examined by RT-qPCR, as described below.

\section{Nucleic acid extraction}

Samples were inactivated upon arrival to the laboratory, by heating at $70{ }^{\circ} \mathrm{C}$ for $30 \mathrm{~min}$. Subsequently, $400 \mu \mathrm{l}$ was 
taken from each sample, mouthwash or ONP swab medium, and then the total nucleic acid content was extracted using magLEAD 12gC (Precision System Science Co. Ltd, Japan) in 50- $\mu$ l elusion buffer.

\section{Real-time PCR}

The presence of the viral RNA was detected using the Seegene Allplex CoV19 detection kit, according to the manufacturer's instructions (http://www.seegene.com/assays/allplex 2019_ncov_assay). Briefly, the test detects three viral genes: envelop (E), nucleocapsid (N), and RNA-dependent RNA polymerase (RdRp). The integrity of the extraction procedure is monitored using an internal control that is inserted into the sample prior to the extraction procedure. The PCR integrity is monitored using a CoV19 positive control. Following mix assembly, the samples were analyzed using the Bio-Rad CFX96 thermal cycler and its accompanying software, CFX Maestro (https://www.bio-rad.com/).

\section{Statistical analysis}

Comparison between the $\mathrm{Cq}$ values obtained for the different reactions performed in the PCR test $(E, N, R)$ for each method (ONP swab/MW) was evaluated by paired samples $t$ test. A $P$ value $<0.05$ was considered statistically significant.

\section{Results}

During a period of 2 months, 137 pairs of samples of MW and ONP swabs were collected. The study included 96 outpatients -38 females and 58 males between ages 18 and 73. Among them, $20.5 \%$ were asymptomatic, while $79.5 \%$ presented with mild symptoms of fever, headache, malaise, cough, myalgia, and more.

\section{Performance of ONP swabs}

Among 137 tests, there were $84.6 \%$ positive cases for at least one of the genes. A Cq value of $\leq 40$ was considered a positive result. Among the 3 tested targets $(\mathrm{N}, \mathrm{E}, \mathrm{R})$, the $\mathrm{N}$ gene reaction was the most sensitive. The $\mathrm{N}$ gene was positive in 114 tests, compared to 95 and 90 in the $\mathrm{E}$ and R genes, respectively. It should be noted that with the exception of two weakly positive tests $(\mathrm{Cq}=38,39)$, whenever $\mathrm{R}$ or $\mathrm{E}$ gene was positive, the $\mathrm{N}$ gene was positive as well (Fig. 1).

\section{Performance of saline MW solution}

Among 137 tests, there were $70.8 \%$ positive cases by at least one of the genes. Among the 3 tested targets (N, E, R), the $\mathrm{N}$ gene reaction seems to be the most sensitive. The $\mathrm{N}$ gene

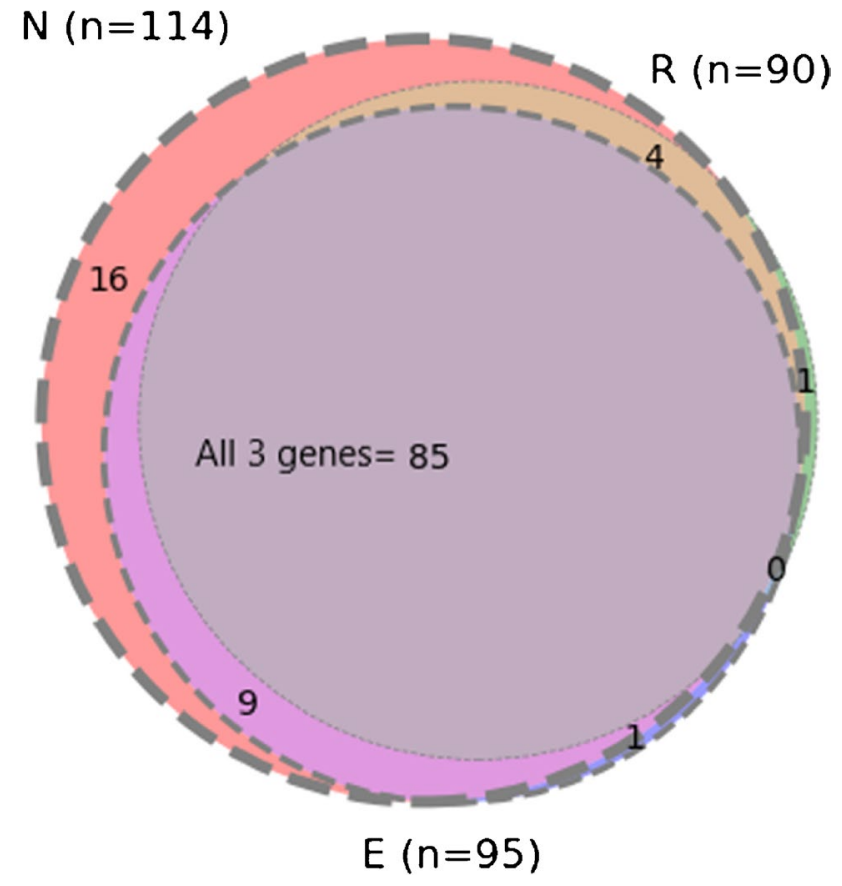

Fig. 1 Number of positive results of oro-nasopharyngeal swab ( $N=137$ tests) in each target (N, E, R genes) and their overlapping

reaction was positive in 95 tests, compared to 69 in both $\mathrm{E}$ and R gene reactions. Similar to the ONP swabs, the N gene reaction was almost always positive when $\mathrm{R}$ or $\mathrm{E}$ reactions were positive, with exception of two weak-positive tests, with high $\mathrm{Cq}$ values $(39,40)$ and negative $\mathrm{N}$ gene target (Fig. 2).

The median of Cq values of all positive ONP swabs (all three genes) was 30 and the average was $29.6(\mathrm{SD} \pm 6.1$ ), compared to a median of 32 and an average 32.2 of positive MW (SD \pm 4.3$)$. While there were positive ONP swabs with negative MW in the same gene, the medians of those positive $\mathrm{Cq}$ values of ONP swabs, which were missed by MW, were 35-36.

Two MW samples were positive $(\mathrm{Cq}=33$ and 38$)$, while the ONP swab was negative by all three genes.

Since the $\mathrm{N}$ gene reaction seemed to be the most sensitive marker for infection, we compared the performance of MW as tested by the $\mathrm{N}$ gene target in comparison to ONP swabs tested positive by each of the three targets E, R, and $\mathrm{N}$ gene. Figure 3 shows that MW tested for the $\mathrm{N}$ target ( $n=95$, out of 137 (69.3\%) samples) detected $3.7 \%$ more samples than the number detected by R target $(65.7 \%, 90$ out of 137 samples) of the swab and equal to the number detected by E target.

Our laboratory considers $\mathrm{Cq}$ values of 40 and below as positive samples, which is the reference of the above results. According to this, the MW detected $83.6 \%$ of positive ONP swabs (Table 1). When comparing the MW 


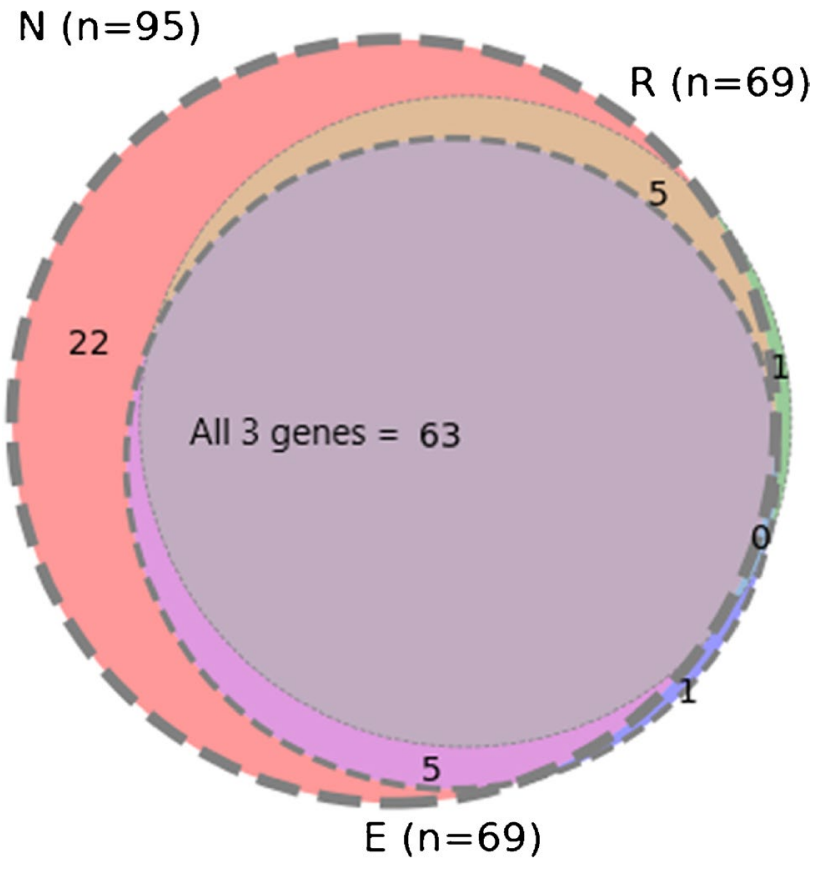

Fig. 2 Number of positive results of saline mouthwash ( $N=137$ tests) in each target (N, E, R genes) and their overlapping

and ONP swabs at a different positive cutoff; $\mathrm{Cq}$ values of 30 and below (higher viral load), which is the accepted threshold of noninfectious state, MW as tested by the $\mathrm{N}$ reaction was positive $(\mathrm{Cq}<40)$ in detecting $94-97 \%$ of these cases.

\section{Other mouth rinse solutions}

\section{Distilled water}

The performance of saline MW was tested in comparison to $10 \mathrm{ml}$ of distilled water.

Since the $\mathrm{N}$ gene reaction appeared to be the most sensitive marker for infection, we compared the performance of MW as tested by the $\mathrm{N}$ target in comparison to water wash tested by $\mathrm{N}$ gene. MW tested by $\mathrm{N}$ target detected 38 tests as positive, out of 59 tests (64\%), which is equal to the detection by water.

The average of $\mathrm{Cq}$ values of all positive saline $\mathrm{MW}$ in the $\mathrm{N}$ target was $33.5(\mathrm{SD} \pm 4.0)$ with a median of 35 , compared to an average of 32.9 in positive water wash in the $\mathrm{N}$ target $(\mathrm{SD} \pm 3.88)$, with a median of 34 .

\section{Other mouthwash solutions}

\section{A. Listerine ${ }^{\circledR}$ - a commercial MW containing alcohol}

Performance of Listerine MW vs saline MW was tested in 12 people who performed the paired tests. The comparison demonstrated that saline MW tested for gene $\mathrm{N}$ was detected in 7 out of 12 tests (58\%), while Listerine MW tested for $\mathrm{N}$ target was detected in only 5 tests as positive, out of 12 tests $(42 \%)$.

The average of $\mathrm{Cq}$ values of all positive saline $\mathrm{MW}$ in the $\mathrm{N}$ target was 31.1 ( $\mathrm{SD} \pm 5.0$ ), with a median of 31, compared to an average of 33.6 in positive Listerine $\mathrm{MW}$ in the $\mathrm{N}$ target $(\mathrm{SD} \pm 3.2)$, with a median of 32 .
Fig. 3 MW as tested by the N target in comparison to ONP swabs tested by N, E, and R targets $(n=137)$. $\mathrm{N}$ gene ONP swab, positive samples of ONP swabs tested by $\mathrm{N}$ target; E gene ONP swab, positive samples of ONP swabs tested by E target; $\mathrm{R}$ gene ONP swab, positive samples of ONP swabs tested by R target; N gene MW, positive samples of MW tested by $\mathrm{N}$ target

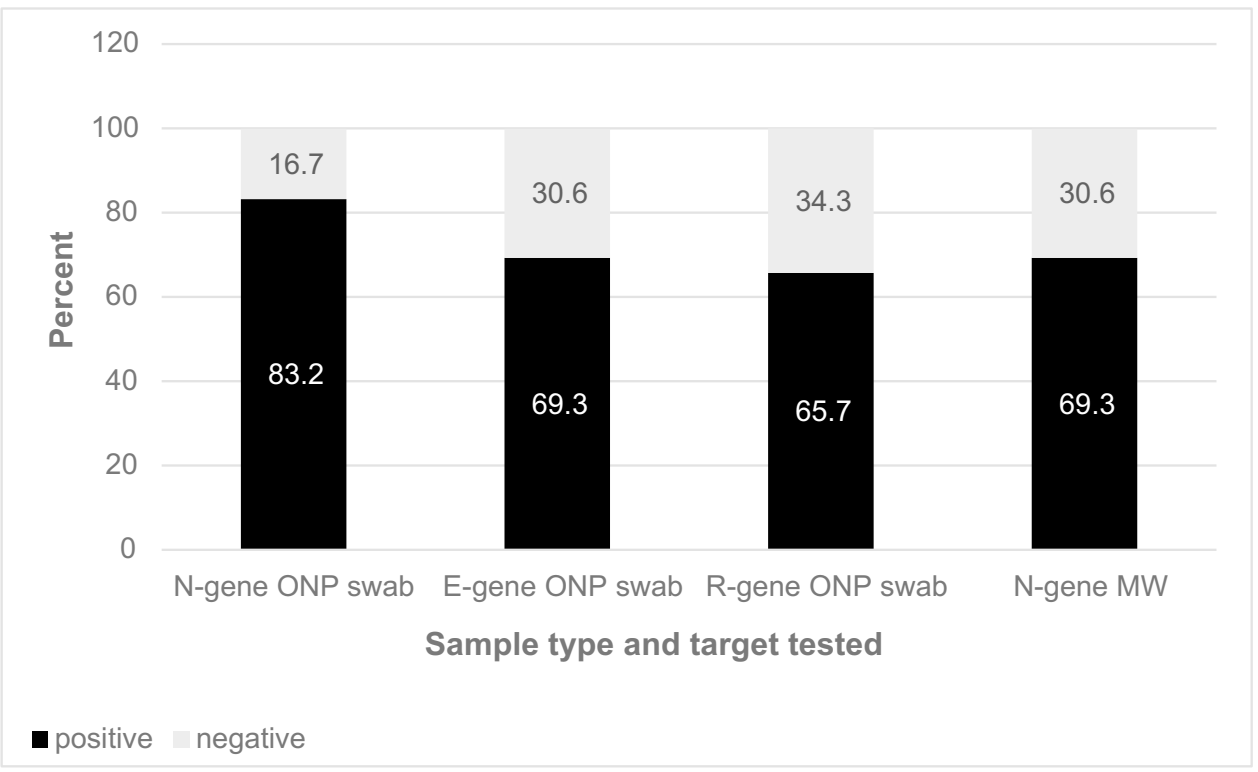


Table 1 Performance of standard ONP gene targets compared to MW target $\mathrm{N}$ gene

\begin{tabular}{|c|c|c|}
\hline & \multicolumn{2}{|l|}{ Positive $\leq 40$} \\
\hline & $\begin{array}{l}\text { Positive/total } \\
\text { Mean Cq }\end{array}$ & $\begin{array}{l}\text { Missing positive cases/ } \\
\text { compared to positive } \mathrm{N} \\
\text { target } \\
\text { Mean Cq (of missed } \mathrm{N} \\
\text { target) }\end{array}$ \\
\hline Swab N target & $\begin{array}{l}114 / 137(83 \%) \\
29.9( \pm 5.9)\end{array}$ & I \\
\hline Swab E target & $\begin{array}{l}95 / 137(69 \%) \\
28.8( \pm 6.5)\end{array}$ & $\begin{array}{l}20 / 114(18 \%) \\
36.3( \pm 2.0)\end{array}$ \\
\hline Swab R target & $\begin{array}{l}90 / 137(66 \%) \\
30.2( \pm 5.9)\end{array}$ & $\begin{array}{l}24 / 114(21 \%) \\
36.4( \pm 1.9)\end{array}$ \\
\hline $\begin{array}{l}\text { MW-N target } \\
\text { (positive } \leq 40 \text { ) }\end{array}$ & $\begin{array}{l}95 / 137(69 \%) \\
32.9( \pm 4.0)\end{array}$ & $\begin{array}{l}22 / 114(19 \%) \\
34.6( \pm 3.5)\end{array}$ \\
\hline
\end{tabular}

\section{B. Orbitol ${ }^{\circledR}$ - a commercial MW without alcohol}

We compared the performance of saline MW as tested for the $\mathrm{N}$ target in comparison to Orbitol MW tested for $\mathrm{N}$ target. The comparison shows that saline MW tested for the $\mathrm{N}$ target detected 13 out of 16 tests $(81 \%)$ as positive, while Orbitol MW tested for the $\mathrm{N}$ target detected 8 out of 16 tests $(50 \%)$ only.
The average of $\mathrm{Cq}$ values of all positive saline $\mathrm{MW}$ in the $\mathrm{N}$ target was $32.9(\mathrm{SD} \pm 3.2)$ with a median of 33, compared to an average of 36.2 in positive Orbitol $\mathrm{MW}$ in the $\mathrm{N}$ target $(\mathrm{SD} \pm 2.9)$ with a median of 36 .

Figure 4 shows the comparison of positive tests in ONP swabs as tested by the $\mathrm{N}$ target alone (as well as by all three gene targets) and the different MW solutions tested in this study.

\section{Discussion}

There is an extensive ongoing research aimed to establish the best sampling test for COVID-19. Thus far, the nucleic acid amplification tests (NAAT) method based on PCR amplification of respiratory sample is the gold standard. CDC guidelines have recommended the performance of swab insertion in specific areas of the respiratory tract such as the nasopharynx, oropharynx, nasal turbinate, and anterior nares [13]. The nasopharyngeal area is still considered the preferred site. However, with its inconvenience, cost, world shortage of supplies, and even safety [14], other sampling methods are urgently needed.

In this study, we compared 137 paired saline MW and ONP swab samples, from 96 confirmed COVID-19 outpatients. Among this group of patients in different stages of their illness, including convalescence samples,

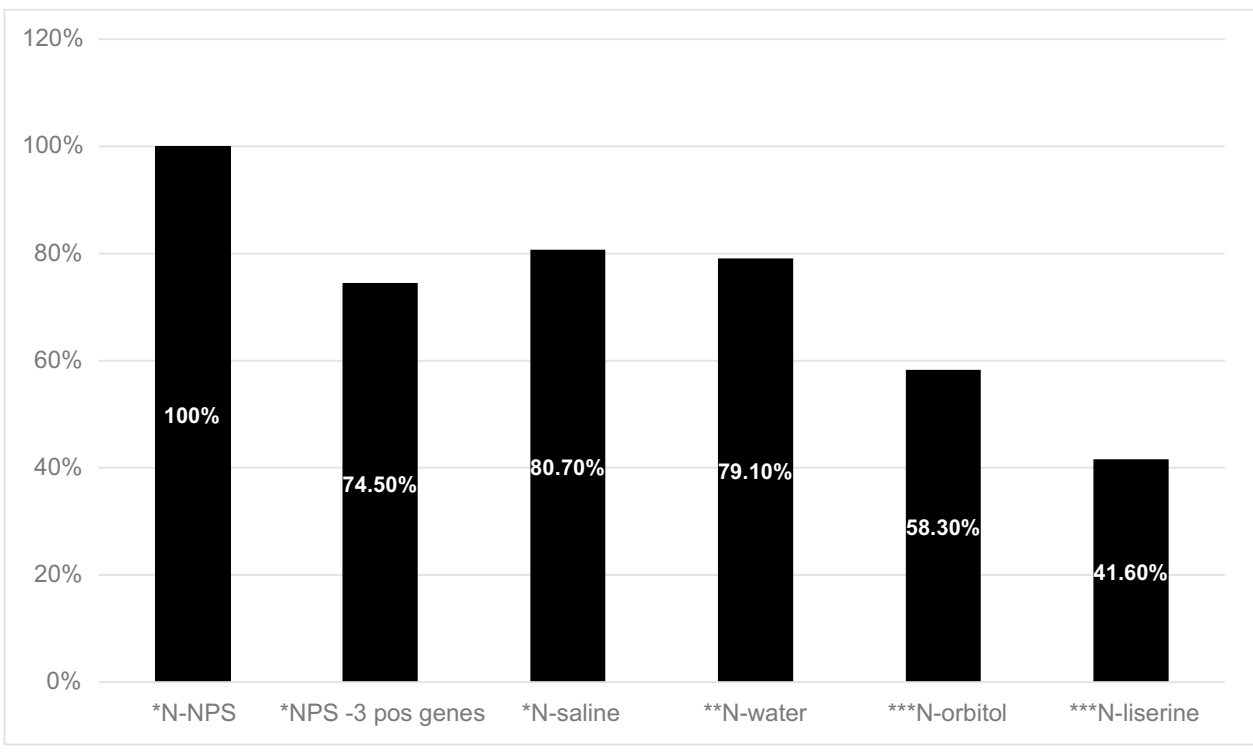

Fig. 4 The performance of different mouth-fluid washes in comparison to positive samples by ONP swabs as tested by N target. N-ONP, positive samples of ONP swabs tested by $\mathrm{N}$ target; ONP-3 pos genes, ONP swabs positive in all 3 gene targets (N,E,R); $\mathrm{N}$ saline, positive samples of saline MW tested by $\mathrm{N}$ target; $\mathrm{N}$ water, positive samples of water MW tested by $\mathrm{N}$ target; $\mathrm{N}$ Orbitol, positive samples of Orbitol MW tested by $\mathrm{N}$ target; $\mathrm{N}$ Listerine, positive samples of Lister- ine MW tested by $\mathrm{N}$ target. *137 samples were tested; among them, 114 were positive in ONP tested by $\mathrm{N}$ target $(=100 \%)$. **59 samples were tested; among them, 48 were positive in ONP tested by $\mathrm{N}$ target $(=100 \%)$. ***16 samples of Orbitol were tested; among them, 12 were positive in ONP tested by N target $(=100 \%)$. Twelve samples of Listerine were tested; among them, 12 were positive in ONP tested by $\mathrm{N}$ target $(=100 \%)$ 
RT-qPCR positivity rate was as high as $84.6 \%$ based on ONP swabs. The results of the main solution examined, MW with normal saline, showed a high detection rateas demonstrated by high positivity rate in comparison to ONP swabs (97 positive MW out of 116 positive ONP swabs, 83.6\%). Negative results were mainly at high $\mathrm{Cq}$ levels [average of 34.4-35], corresponding to the convalescence stage of the disease when patients are not considered infective $[15,16]$.

Our results showed a positivity rate of $83.6 \% \mathrm{MW}$ samples in relation to positive ONP swabs upon using Cq cutoff of $\leq 40$ (being considered negative), yet a comparison with ONP swabs cutoff of $\leq 30$ (higher viral load) yielded much better results of N-MW. It is important to mention that the new antigen rapid diagnostic tests which are commonly used are considered less sensitive than RT-PCR. The sensitivity ranges from 0 to $94 \%$, depending on the viral load in the specimen. However, the value of these antigen tests is the ability to detect viral load of $\mathrm{Cq} \leq 30$, which is considered infectious state [16-18].

Another important finding in our study was the higher sensitivity of the $\mathrm{N}$ gene reaction (84\%), compared to $\mathrm{E}$ (69\%) and R (65\%) reactions, by ONP swabs. Different laboratories and organizations around the world use different RT-qPCR tests with different target genes, to detect SARS$\mathrm{CoV}-2$. Some use a single target assay, targeting the R gene, the E gene, the Orf1ab region, or other viral genes. The clinical sensitivity varies between kits [19], thereby potentially leading to false-negative results, especially with low viral loads. The high sensitivity of $\mathrm{N}$ gene reaction implemented in the Seegene kit was reflected both in the ONP swabs and MW tests. The MW tested by N gene reaction ( $n=95 ; 69 \%$ positivity rate) appears to be superior to $\mathrm{R}$ reaction in ONP swab $(n=90 ; 66 \%)$ and equivalent to the E reaction $(n=95$; $69 \%)$.

Notably, our comparison was performed where the swab sampling was based on oral and nasopharyngeal sampling, which is considered the most sensitive approach, while other countries use different collection sites (nasopharynx, nasal turbinate, anterior nares).

Additionally, dedicated professional staff performed the procedure; thus, we most likely obtained the best possible results. Moreover, the MW sampling was always performed before the ONP swab, to avoid falsely raising the amount of epithelial cells in the MW. The high positivity rate of the MW in our study (specifically the $\mathrm{N}$ target) may therefore offer an alternative for ONP especially in situations where there is shortage of swab sampling resources, it has no side effects compared to ONP swabs [14], and the MW can be easily self-collected.

We compared normal saline MW with other solutions, and none were found to be superior. Water MW had an equal performance to saline MW in contrast to other solutions, which had lower detection rate. We assumed that fluids that contain lipids and alcohol (Listerine ${ }^{\circledR}$ ) rinse off the epithelial cells of the oro-nasopharynx, thus producing more positive samples. However, in practice, the results showed low positivity rate, similarly to non-alcohol containing solution (Orbitol®), which resulted in low positivity rate.

In the past, studies have examined the effectiveness of gargle samples for the molecular detection of respiratory infections. Results were overall encouraging regarding the sensitivity of mouthwash compared to saliva sampling or nasopharyngeal swab, although not consistently and patient sample was very small in some of the studies (Table 2).

Numerous saliva testing studies have been conducted comparing it to different respiratory tract swab testing. Results are conflicting but there is FDA approval for some of these methods. [12] However, saliva testing is less convenient for the patients [25], and might be more complicated to process in the lab due to its high viscosity and presence of inhibitory saliva proteins [26], which may further increase laboratory workload.

Table 2 Mouthwash performance in detecting different respiratory pathogens

\begin{tabular}{|c|c|c|c|}
\hline Pathogen & Comparison between sampling methods & Results & Reference \\
\hline $\begin{array}{l}\text { Varies respiratory pathogens - the most } \\
\text { dominant was influenza A (18), then } \\
\text { influenza B (11), and RSV (6) }\end{array}$ & 79 NP swabs vs 79 mouthwashes & $\begin{array}{l}\text { Mouthwashes demonstrated higher sen- } \\
\text { sitivity } \\
18 \text { positive washes with negative swabs } \\
(\mathrm{Cq}>29), 8 \text { positive swabs with negative } \\
\text { washes }(\mathrm{Cq}>28)\end{array}$ & {$[20]$} \\
\hline COVID-19 & 24 NP swabs vs 24 mouthwashes & $\begin{array}{l}5 \text { mouthwashes were positive with nega- } \\
\text { tive swabs }\end{array}$ & {$[21]$} \\
\hline Mycobacterium tuberculosis & $\begin{array}{l}127 \text { mouthwashes vs } 127 \text { sputum speci- } \\
\text { mens }\end{array}$ & $\begin{array}{l}\text { Mouthwash was less sensitive than sputum } \\
\text { specimens ( } 73 \% \text { vs } 99 \% \text { ) }\end{array}$ & {$[22]$} \\
\hline SARS & 17 mouthwash vs 17 saliva samples & $\begin{array}{l}17 \text { mouthwashes were positive vs } 14 \text { posi- } \\
\text { tive saliva samples }\end{array}$ & {$[23]$} \\
\hline SARS & $\begin{array}{l}17 \text { mouthwashes of serology confirmed } \\
\text { SARS patients }\end{array}$ & 11 mouthwashes were positive out of 17 & {$[24]$} \\
\hline
\end{tabular}


Comparing the different methods of obtaining respiratory tract samples is therefore a complicated task due to the high number of variables. It depends on whether a swab is taken by a medical personnel or by self-testing. It also depends on the part of the respiratory tract from which the sample is obtained-nasopharynx, oropharynx, nasal turbinate, or anterior nares-since there were different results [27].

The idea of self-collected specimens was examined in a study which compared nasopharyngeal swab and at least one self-collected sample-saline mouth rinse or saliva. Saline mouth rinse samples had a sensitivity of 98\% (39/40) compared to $79 \%(26 / 33)$ of saliva samples. In addition, when patients ranked the sample acceptability $(1=$ lowest, $5=$ highest , the mouth rinse had the highest mean acceptability (4.95), significantly more acceptable than healthcare worker collected NP swab (3.17) or saliva sampling (4.44) [25].

\section{Limitations}

Our study included COVID-19 outpatients, most of them with mild symptoms; thus, the study population did not reflect a population suitable for screening measures, nor did it include children. Nevertheless, there were different degrees of illness and many negative patients (in the convalescence stage) to compare the different methods among healthy subjects. The RT-qPCR assay used here included three different targets (N, E, R), which may be complicated to analyze and cannot be implemented in many laboratories. Therefore, if MW sampling will be used widely, in many cases, it may not be tested by the Seegene $\mathrm{N}$ reaction, as our results suggest it is beneficial, for sensitive detection.

On the other hand, our comparison is advantageous since the MW was compared to ONP swab (and not just NP swab), presumably the most sensitive method currently used as a standard. This sampling was performed by professional personnel, and not by the patient himself/herself, and the samples were all analyzed at the same laboratory. Under these strict conditions, we found evidence that support the effectiveness of MW as an alternative sampling method. We therefore speculate that when swabs are self-collected, or taken from only one area (nasopharynx, oropharynx, nasal turbinate, or anterior nares), there is a high probability that the MW will perform even better, in terms of sensitivity, than the swab sampling.

The results described herein suggest that using the least expensive and more convenient approach, by saline MW sampling, may be a reliable alternative for swab testing, with high positivity rate- $83.6 \%$ out of positive ONP swabs. Our finding that saline MW sampling is a reliable method of detecting SARS-CoV-2 may therefore be successfully used for diagnosis of other respiratory pathogens.

\section{Data and materials availability}

Data will be made available on reasonable request.

Author contribution D.L., A.B., O.E., E.S.: literature review, manuscript drafting. A.B, M.M, G.H, A.S, O.E: collecting data. D.L, A.B, M.M, O.E, Y.L, E.S: interpretation of data. D.L, Y.L, O.E, E.S.: critical review.

\section{Declarations}

Ethics approval Ethical approval was obtained from Sheba Medical Center. The trial was done in accordance with the principles of the Declaration of Helsinki.

Consent to participate Informed consent was obtained from all patients.

Consent for publication The manuscript has been seen and approved by all authors, who accept full responsibility for the content. The authors had full access to the data and their analysis, as well as drafting the article or editing an author's draft.

Conflict of interest The authors declare no competing interests.

\section{References}

1. World Health Organization (2020) Weekly Operational Update on COVID-19, 4 September 2020. World Health Organization $1: 6$

2. Tromberg BJ, Schwetz TA, Pérez-Stable EJ et al (2020) Rapid scaling up of Covid-19 diagnostic testing in the United States the NIH RADx initiative. N Engl J Med 383(11):1071-1077

3. Pan Y, Zhang D, Yang P, Poon LLM, Wang Q (2020) Viral load of SARS-CoV-2 in clinical samples. Lancet Infect Dis 20(4):411-412

4. Zou L, Ruan F, Huang M et al (2020) SARS-CoV-2 viral load in upper respiratory specimens of infected patients. N Engl J Med 382(12):1177-1179

5. To KK, Tsang OT, Leung WS et al (2020) Temporal profiles of viral load in posterior oropharyngeal saliva samples and serum antibody responses during infection by SARS-CoV-2: an observational cohort study. Lancet Infect Dis 20(5):565-574

6. Wölfel R, Corman VM, Guggemos W et al (2020) Virological assessment of hospitalized patients with COVID-2019. Nature 581(7809):465-469

7. Sethuraman N, Jeremiah SS, Ryo A (2020) Interpreting diagnostic tests for SARS-CoV-2. JAMA 323:2249-2251

8. Czumbel LM, Kiss S, Farkas N et al (2020) Saliva as a candidate for COVID-19 diagnostic testing: a meta-analysis. Front Med (Lausanne) 4(7):465

9. Jamal AJ, Mozafarihashjin M, Coomes E, et al (2020) Sensitivity of nasopharyngeal swabs and saliva for the detection of severe acute respiratory syndrome coronavirus 2 (SARSCoV-2). Clin Infect Dis ciaa848

10. Wyllie AL, Fournier J, Casanovas-Massana A et al (2020) Saliva or nasopharyngeal swab specimens for detection of SARS-CoV-2. N Engl J Med. https://doi.org/10.1056/NEJMc 2016359 
11. Yale School of Public Health, Department of Epidemiology of Microbial Diseases (2020) Accelerated emergency use authorization (EUA) summary sars-cov-2 RT-PCR assay. FDA, August 25, 2020

12. Centers for Disease Control and Prevention (2020) Interim guidelines for collecting, handling, and testing clinical specimens for COVID-19. $C D C$ nov 2020

13. CDC (2020) Information for laboratories about coronavirus (COVID-19). Cent Dis Control Prev. https://www.cdc.gov/ coronavirus/2019-ncov/lab/guidelines-clinical-specimens.html. Accessed 3 Nov 2020

14. Fabbris C, Cestaro W, Menegaldo A, et al (2021) Is oro/nasopharyngeal swab for SARS-CoV-2 detection a safe procedure? Complications observed among a case series of 4876 consecutive swabs. Am J Otolaryngol 42(1)

15. Walsh KA, Spillane S, Comber L et al (2020) The duration of infectiousness of individuals infected with SARS-CoV-2. J Infect S0163-4453(20):30651-30654

16. Mina MJ, Parker R, Larremore DB (2020) Rethinking Covid-19 test sensitivity - a strategy for containment. N Engl J Med

17. World Health Organization (2020) SARS-CoV-2 antigen-detecting rapid diagnostic tests: an implementation guide. World Health Organization 22-24

18. Regev-Yochay G, Kriger O, Beni S et al (2020) Real world performance of SARS-CoV-2 antigen rapid diagnostic tests in various clinical settings. medRxiv [Preprint]. https://doi.org/10.1101/2021. 03.02 .21252400

19. Van Kasteren PB, van der Veer B, van den Brink S, et al (2020) Comparison of seven commercial RT-PCR diagnostic kits for COVID-19. J Clin Virol. 128:104412

20. Bennett S, Davidson RS, Gunson RN (2017) Comparison of gargle samples and throat swab samples for the detection of respiratory pathogens J Virol Methods 248:83-86
21. Guo WL, Jiang Q, Ye F, et al (2020) Effect of throat washings on detection of 2019 novel coronavirus. Clin Infect Dis 71(8):1980-1981

22. Davis JL, Huang L, Kovacs JA et al (2009) Polymerase chain reaction of secA1 on sputum or oral wash samples for the diagnosis of pulmonary tuberculosis. Clin Infect Dis 48(6):725-732

23. Wang WK, Chen SY, Liu IJ et al (2004) Detection of SARS-associated coronavirus in throat wash and saliva in early diagnosis. Emerg Infect Dis 10(7):1213

24. Liu IJ, Chen PJ, Yeh SH et al (2005) Immunofluorescence assay for detection of the nucleocapsid antigen of the severe acute respiratory syndrome (SARS)-associated coronavirus in cells derived from throat wash samples of patients with SARS. J Clin Microbiol 43(5):2444-2448

25. Goldfarb DM, Tilley P, Al-Rawahi GN et al (2021) Self-collected saline gargle samples as an alternative to healthcare worker collected nasopharyngeal swabs for COVID-19 diagnosis in outpatients. J Clin Microbiol 59(4):e02427-e2520

26. Wyllie AL, Fournier J, Casanovas-Massana A, et al (2020) Saliva or nasopharyngeal swab specimens for detection of SARS-CoV-2. N Engl J Med 383(13):1283-1286

27. Hanson KE, Barker AP, Hillyard DR et al (2020) Self-collected anterior nasal and saliva specimens versus healthcare workercollected nasopharyngeal swabs for the molecular detection of SARS-CoV-2. J Clin Microbiol 58(11):e01824-e1920

Publisher's note Springer Nature remains neutral with regard to jurisdictional claims in published maps and institutional affiliations. 